\title{
Estimativas do rendimento de farinha e de amido em mandioca
}

\author{
Augusto Carlos Pola' ${ }^{1}$ Eduardo da Costa Nunes² e Alexsander Luis Moreto²
}

Resumo - Através de análise de regressão linear, foram desenvolvidas equações e gráficos que possibilitam estimativas do rendimento de farinha fina para as regiões Sul Catarinense e Vale do Itajaí, em Santa Catarina, Brasil. Em outro estudo de regressão linear, foi gerado um modelo matemático para estimativa do rendimento em amido das raízes a partir do seu teor de matéria seca. O método utilizado apresentou uma eficiência de extração de amido de $66 \%$, ou seja, cerca de um terço do amido ficou retido no resíduo. Considerando uma eficiência de extração industrial próxima deste valor, é possível utilizar a equação gerada para estimar a produção de fécula a partir do teor de matéria seca das raízes tuberosas. Foram também determinados, no presente trabalho, os teores de matéria seca e o rendimento em amido das raízes de cinco cultivares comerciais de mandioca do Sul de Santa Catarina, colhidas após um e dois ciclos vegetativos. Foram registrados incrementos médios de 8,4\% e 5,1\% pontos porcentuais no teor de matéria seca e no rendimento em amido, respectivamente, ao final do segundo ciclo de cultivo.

Termos para indexação: Manihot esculenta Crantz; Fécula; Rendimento industrial.

\section{Estimates of flour and starch yield of cassava roots}

Abstract - Through linear regression analysis, equations and graphs were developed that allow estimates of flour yield for the Sul Catarinense and Vale do Itajaí regions, in Santa Catarina, Brazil. In another linear regression study, a mathematical model was generated to estimate the starch yield of the roots from their dry matter content. The method used showed a starch extraction efficiency of $66 \%$, that is, about one third of the starch was retained in the residue. Considering an industrial extraction efficiency close to this value, it is possible to use the equation generated to estimate the production of industrial starch yield from the dry matter content of the tubers. The contents of dry matter and starch of the roots of five commercial cassava cultivars in the south of Santa Catarina, harvested after one and two vegetative cycles, were also determined in this work. Average increases of $8.4 \%$ and $5.1 \%$ percentage points were recorded in the dry matter content and in the starch yield at the end of the second cultivation cycle.

Index terms: Manihot esculenta Crantz; Starch; Industrial yield.

O teor de matéria seca é um dos mais importantes critérios utilizados para avaliar a qualidade de raízes de mandioca destinadas ao beneficiamento industrial. Isso ocorre porque esta característica está diretamente relacionada ao rendimento final de farinha ou fécula. A indústria mandioqueira geralmente utiliza o teor de matéria seca das raízes tuberosas para definir o preço a ser pago pela tonelada de raízes ao agricultor. A sua determinação pode ser utilizada, também, para definir o melhor momento do início ou da paralisação da colheita, permitindo melhor planejamento e otimização da capacidade industrial. No Brasil e no mundo, a principal metodologia utilizada para a estimativa da matéria seca das raízes é a da balança hidrostática, também cha- mada de gravidade específica (CEREDA et al., 2003). O teor de matéria seca, neste caso, é estimado a partir do peso de raízes imersas em água.

Objetivou-se com o presente trabalho determinar os teores de matéria seca e o rendimento em amido, bem como desenvolver equações para a estimativa do rendimento de farinha nas raízes tuberosas de cultivares comerciais de mandioca em regiões de Santa Catarina.

As determinações de matéria seca (MS) e amido (A) do presente trabalho foram realizadas por meio do método de secagem em estufa, conforme metodologia descrita por Pola et al. (2020). Para compor uma amostra, foram retirados $500 \mathrm{~g}$ de toletes da polpa do terço médio de cerca de oito raízes. Esta amostra de $500 \mathrm{~g}$ foi triturada em liquidificador industrial com um volume de água de 2,5 litros. Após este processo, a massa obtida foi submetida a um processo de filtração com prensagem em tecido tipo "voil", separando-se, após cinco lavagens sucessivas, o amido que ficou disperso na água de lavagem e o resíduo que ficou retido no tecido. $O$ amido foi separado do líquido sobrenadante após 24 horas de decantação. Este amido e o resíduo foram colocados a secar em estufa, a $45^{\circ} \mathrm{C}$ e $70^{\circ} \mathrm{C}$, respectivamente, até peso constante. $\mathrm{O}$ rendimento em amido da amostra (A), em porcentagem, foi calculado por $A=p_{A} / 5$, onde $p_{A}$ é o peso do amido, em gramas, após a secagem em estufa. A porcentagem de matéria seca da amostra (MS) foi determinada por $M S=\left(p_{A}+p_{R}\right) / 5$, onde $p_{R}$ é 
o peso do resíduo, em gramas, após a secagem em estufa. O rendimento de extração do amido (RE), em porcentagem, foi calculado por $R E=100(A / M S)$.

As raízes foram colhidas mensalmente, de 10 a 20 meses após o plantio (MAP), em uma área localizada no município de Jaguaruna, estado de Santa Catarina, em um Neossolo quartzarênico. Os cultivares utilizados constam na Tabela 1.

Os cultivares Sambaqui e Sangão apresentaram os maiores teores de matéria seca e de rendimento em amido nas raízes, tanto ao final do primeiro (10 MAP) como do segundo ciclo de cultivo (20 MAP), como pode ser observado na Tabela 1. Em média, foram observados incrementos de $8,4 \%$ e $5,1 \%$ pontos porcentuais nos teores de matéria seca e no rendimento em amido (base úmida), respectivamente, ao final do segundo ciclo vegetativo em relação ao primeiro. Os teores de matéria seca, após dois ciclos de cultivo, podem se manter constantes com relação ao primeiro, como observado por Mondardo et al. (2001), ou até diminuir, em razão de fatores genéticos, condições edafoclimáticas, manejo da cultura e ocorrência de pragas e doenças (POLA et al., 2017).

Na Figura 1 é apresentada a relação entre o rendimento em amido e o teor de matéria seca, obtida no presente trabalho a partir das amostragens mensais das cinco variedades. Como pode ser observado, existe uma correlação forte entre as duas variáveis $(R=0,95)$. As amostras utilizadas na regressão linear da Figura 1 apresentaram uma média de $31,8 \%$ de matéria seca e $21,1 \%$ de amido extraído nas condições do presente estudo. O método laboratorial de extração de amido, portanto, apresentou uma eficiência média de $66,3 \%$ em relação à matéria seca das raízes.

O rendimento industrial de extração do amido depende da tecnologia adotada (equipamentos e processo), além da qualidade da raiz processada em termos de teor de matéria seca e de amido (ALVES \& VEDOVOTO, 2003). No processamento de uma fecularia, cerca de um terço do amido das raízes fica retido no resíduo, obtendo-se cerca de $255 \mathrm{~kg}$ de fécula para cada tonelada de raiz processada (LEBOURG,1996; LEONEL \& CEREDA, 2000). No balanço de massa
Tabela 1. Teores de matéria seca (MS), rendimento em amido (A) e rendimento de extração de amido (RE), de raízes tuberosas de cinco cultivares de mandioca, ao final do primeiro ciclo vegetativo em julho (10 MAP) e ao final do segundo ciclo em maio (20 MAP). Jaguaruna, SC, julho de 2016 e maio de 2017

Table 1. Dry matter content (MS) and starch yield (A), on a wet basis, and starch extraction efficiency (RE), from tuberous roots of five cassava cultivars, at the end of the first vegetative cycle in July (10 MAP) and at the end of the second cycle in May (20 MAP). Jaguaruna, SC, July 2016 and May 2017

\begin{tabular}{|c|c|c|c|c|c|c|}
\hline & Sangão & Sambaqui & $\begin{array}{l}\text { Olho } \\
\text { Junto }\end{array}$ & $\begin{array}{c}\text { Mandim } \\
\text { Branca }\end{array}$ & Luna & MÉDIA \\
\hline MS (\%) 1 ciclo & $31,74 \mathrm{a}$ & 29,25 a & $27,85 b$ & $25,44 b$ & $22,78 \mathrm{c}$ & 27,41 \\
\hline MS (\%) 2 ciclos & 39,26 a & 38,34 a & $33,68 \mathrm{~b}$ & $33,84 b$ & $33,77 b$ & 35,79 \\
\hline A (\%) 1 ciclo & $22,10 a$ & $20,21 \mathrm{a}$ & $19,57 b$ & $18,05 \mathrm{~b}$ & $15,85 \mathrm{c}$ & 19,16 \\
\hline A (\%) 2 ciclos & $26,20 \mathrm{a}$ & $25,12 \mathrm{a}$ & $23,36 b$ & $23,36 \mathrm{~b}$ & $23,51 b$ & 24,31 \\
\hline RE (\%) 1 ciclo & 70 & 69 & 70 & 71 & 70 & 70,0 \\
\hline RE (\%) 2 ciclos & 67 & 66 & 69 & 69 & 70 & 68,0 \\
\hline
\end{tabular}

$\mathrm{RE}=100(\mathrm{~A} / \mathrm{MS}) ; \mathrm{MAP}-$ Meses após o plantio. Cada valor representa a média de três repetições. Médias seguidas da mesma letra na linha não apresentam diferenças estatisticamente significativas entre si pelo teste de Scott e Knott ao nível de 5\%.

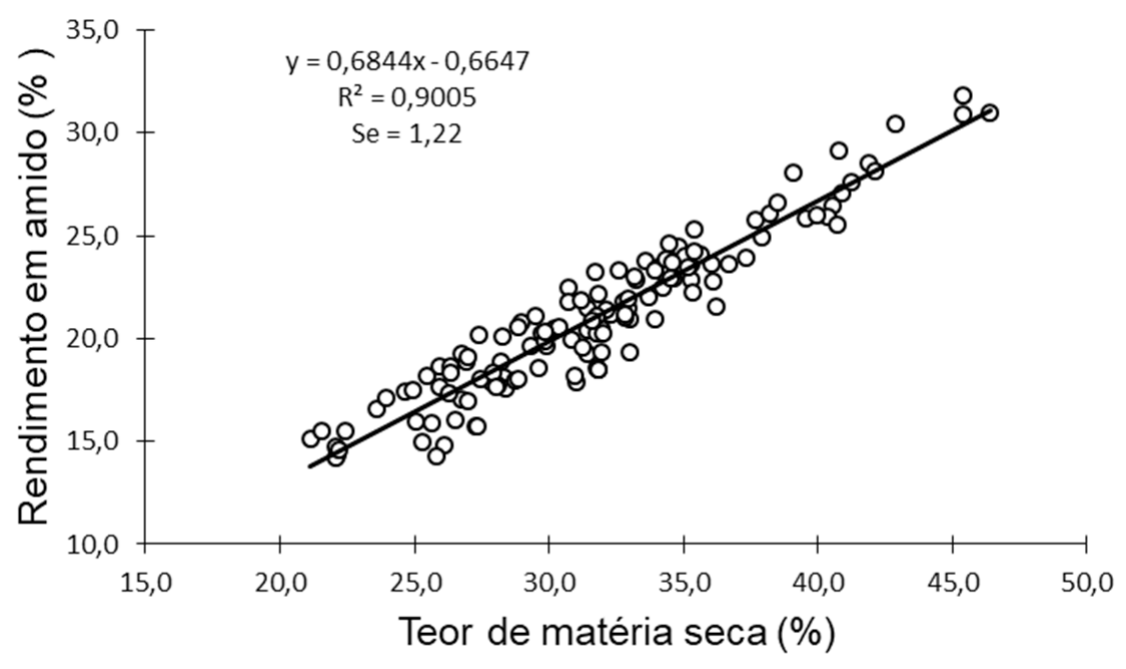

Figura 1. Regressão linear entre o teor de matéria seca (variável independente) e o rendimento em amido (variável dependente), de raízes tuberosas de cinco cultivares de mandioca, colhidas mensalmente de 10 a 20 meses após o plantio. Rendimento médio de extração de amido (base seca) $=66,3 \%$. Jaguaruna, SC, julho de 2016 a junho de 2017 . Se $=$ erro padrão da estimativa.

Figure 1. Linear regression between the dry matter content (independent variable) and the starch content (dependent variable), on a wet basis, of tuberous roots of five cassava cultivars, harvested monthly from 10 to 21 months after planting. Average yield of starch extraction (dry basis) $=66.3 \%$. Jaguaruna, SC, July 2016 to June 2017. Se = Estimate standard error. 
de uma fecularia apresentado por Lebourg (1996), a eficiência de extração de amido das raízes, em relação à matéria seca, foi de $69 \%$. Estes rendimentos são semelhantes aos obtidos, em termos médios, no presente trabalho. Assim, a equação linear que consta na Figura 1 pode ser utilizada para estimar o rendimento de fécula de uma fecularia a partir do teor de matéria seca das raízes, considerando-se uma eficiência de extração industrial próxima de $66 \%$.

Na Figura 2 são apresentados dois gráficos que relacionam o peso de $3,0 \mathrm{~kg}$ de raízes imersas em água com o rendimento de farinha fina, expresso em sacas de $50 \mathrm{~kg}$ por tonelada de raízes. A farinha foi obtida com a utilização de um engenho de prova (TERNES, 1986), a partir das amostras de 3,0kg de raízes. $\mathrm{Na}$ Figura 2A foram utilizadas raízes coIhidas cerca de 9 meses após o plantio, em Jaguaruna, SC, nos anos de 1985 a 1990 e em 1994 e 1995, totalizando 103 amostras. Na Figura 2B foram utilizadas raízes de um e dois ciclos produtivos provenientes de municípios da região do Vale do Itajaí, SC (Itajaí, Brusque, Ituporanga e Agrolândia), colhidas nos anos de 1985 a 1987 e em 1991, totalizando 110 amostras. Para comparação, nas citadas figuras consta um segmento de reta, representado por uma linha tracejada, relativo aos resultados obtidos por Fukuda \& Caldas (1987) com 310 variedades de um banco de germoplasma de mandioca em Cruz das Almas, BA. Estes autores obtiveram um coeficiente de determinação $R^{2}$ de 0,61 . Pode ser observado na Figura 3 que os resultados de regressão linear do presente estudo, representados pelas linhas cheias nos gráficos A e B, são próximos aos da linha pontilhada, indicando resultados semeIhantes aos obtidos na Bahia. Portanto, as equações e os gráficos apresentados na Figura 2 podem ser utilizados para estimar o rendimento de farinha a partir do peso das raízes imersas em água.

Foi observado que o teor de carolo das amostras beneficiadas (resíduo da farinha após a peneiração) foi um dos fatores responsáveis pelas variações dos pontos em torno das retas dos gráficos A e B. A utilização do método do peso específico também deve ter contribuído para as variações observadas, em razão de que este método pode não
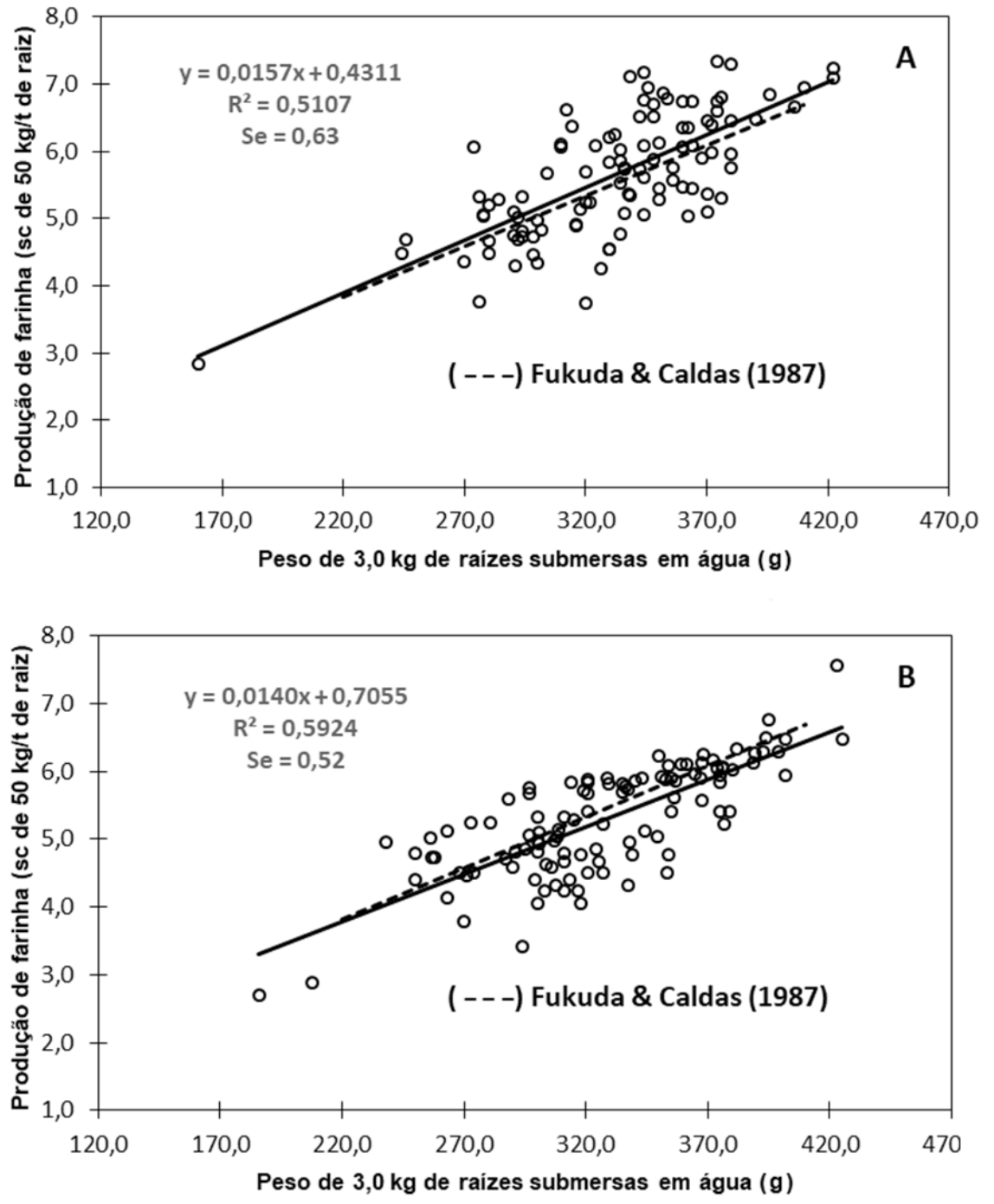

Figura 2. Regressão linear entre a produção de farinha de mandioca fina, em sacos de $50 \mathrm{~kg}$ por tonelada de raízes (variável dependente "y") e o peso de 3,0kg de raízes imersas em água, em gramas (variável independente " $x$ ") de raízes de um ciclo vegetativo colhidas em Jaguaruna, SC (Figura A) e de um e dois ciclos vegetativos colhidas na mesorregião do Vale de Itajaí, SC (Figura B). A linha tracejada representa a equação obtida por Fukuda \& Caldas (1987). Se = erro padrão da estimativa.

Figure 2. Linear regression between the production of fine cassava flour, in $50 \mathrm{~kg}$ bags per ton of root (dependent variable " $y$ ") and the weight of $3.0 \mathrm{~kg}$ of roots submerged in water, in grams (independent variable " $x$ ") from roots of one vegetative cycle harvested in Jaguaruna, SC (Figure A) and from one and two vegetative cycles harvested in the mesoregion of Vale de Itajai, SC (Figure B). The dashed line represents the equation obtained by Fukuda \& Caldas (1987). Se = Estimate standard error.

determinar com precisão o teor de matéria seca das raízes (JUSTE JUNIOR et al., 1983; CARVALHO et al., 2007; POLA et al., 2020). De maneira geral, fatores genéticos, manejo da cultura, época de colheita, clima e solo, entre outros, também podem contribuir para estas variações.

A equação e gráfico presentes na Figura 1 possibilitam a estimativa do rendimento de amido das raízes a partir do seu teor de matéria seca. As equações constantes na Figura 2, por sua vez, permitem estimativas do rendimento de farinha a partir do peso de 3,0kg de raízes imersas em água. Em ambos os casos, deve-se considerar as condições experimentais e os métodos utilizados no presente trabalho. É importante salientar que a utilização de um número 
adequado de repetições (amostras) proporcionará uma estimativa mais precisa do rendimento médio final de amido ou farinha.

O rendimento percentual em amido apresentou uma elevada correlação linear com o teor de matéria seca das raízes obtido em laboratório $(R=0,95)$. Embora o rendimento em farinha não tenha apresentado correlações tão elevadas com o peso de $3,0 \mathrm{~kg}$ de raízes submersas em água ( $R=0,73$, em média), a simplicidade do método da gravidade específica o qualifica para a obtenção de estimativas rápidas e, inclusive, a campo.

\section{Referências}

ALVES, E.R. de A.; VEDOVOTO, G.L. A indústria do amido de mandioca. Brasília: Embrapa, 2003. 201p. (Documentos, 6). Disponível em: https://www.infoteca.cnptia.embrapa. br/infoteca/bitstream/doc/109712/1/Industriaamidomandioca.pdf. Acesso em: 12 nov. 2019.

CARVALHO, P.R.N.; MEZZETTE, T.F.; VALLE, T.L.; CARVALHO, C.L.R.; FELTRAN, J.C. Avaliação da exatidão, precisão e robustez do método de análise do teor de matéria seca de mandioca (Manihot esculenta, Crantz) por meio da determinação do peso específico (balança hidrostática). Revista Raízes e Amidos Tropicais, Botucatu, v.3, p.1-4, 2007. Disponível em: http://energia.fca.unesp.br/ index.php/rat/article/view/1313. Acesso em: 8 out. 2019.

CEREDA, M. P.; VILPOUX, O. \& TAKAHASHI, $M$. Balança hidrostática como forma de avaliação do teor de massa seca e amido. In CEREDA, M. P. \& VOLPOUX, O. Tecnologia, usos e potencialidade de tuberosas amiláceas latino-americanas. São Paulo - Fundação Cargill, v.3. n.2 p. 30-47, 2003.

FUKUDA, W.M.G.; CALDAS, R.C. Relação entre os conteúdos de amido e farinha em mandioca. Revista Brasileira de Mandioca, Cruz das Almas, v.6, n.2, p.57-63, 1987.

JUSTE JUNIOR, E.S.G.; CARVALHO, V.D. de; VILELA, E.R.; CLEMENTE, P.R.; CORREA, H. MORAES, MORAES, A.R. de. Comparação entre o método físico da balança hidrostática e métodos químicos na determinação de amido em raízes de mandioca. Pesquisa Agropecuária Brasileira, Brasília, v.18, n.1, p.55-57, 1983. Disponível em: https:// seer.sct.embrapa.br/index.php/pab/article/ view/15150/8933. Acesso em: 12 dez. 2019.

LEBOURG, C. Brasamide et la fécule: une historie d'amour. Botucatu: Centro de Raízes Tropicais, UNESP, 1996. 59p.
LEONEL, M.; CEREDA, M.P. Extração da fécula retida no resíduo fibroso do processo de produção de fécula de mandioca. Ciência e Tecnologia de Alimentos, Campinas, v.20, n.1, p.122-127, 2000. Disponível em: http://dx.doi.org/10.1590/S010120612000000100023. Acesso em: 27 nov. 2019.

MONDARDO, E.; LAVINA, M.L.; DITTRI$\mathrm{CH}$, R.C. Variação Sazonal na produção de mandioca em solo Areias Quartzosas Distróficas, na Região Sul Catarinense. Florianópolis: Epagri, 2001. 33p. (Epagri, Boletim Técnico, 116).

POLA. A.C.; MORETO, A.L.; NUNES, E.C.; PERUCH, L.A.M.; NEUBERT, E.O. Variações na produtividade e matéria seca de raízes de mandioca em função da época de colheita. Agropecuária Catarinense, Florianópolis, v.30, n.3, p.79-83, 2017. Disponível em: https://publicacoes.epagri.sc.gov.br/RAC/article/view/149/149. Acesso em: 26 nov. 2020.

POLA, A.C.; NUNES, E.C.; MORETO, A.L. Matéria seca em raízes de mandioca determinada pelos métodos da balança hidrostática e de secagem em estufa. Agropecuária Catarinense, Florianópolis, v.33, n.1, p.56-60, 2020. Disponível em: https://publicacoes. epagri.sc.gov.br/RAC/article/view/533/707. Acesso em: 27 nov. 2020 .

\section{Avalie regularmente a qualidade da água que você consome.}

Laboratórios de Análises de Águas:

Fone : (49) 3328-4277

E-mail: cepaf@epagri.sc.gov.br Chapecó, SC

Fone: (48) 3465-1933

E-mail: eeur@epagri.sc.gov.br Urussanga, SC

Fone: (49) 3341-5244

E-mail: eei@epagri.sc.gov.br Itajaí, SC 